\title{
Shear Band Formation in an FCC Crystal Containing Mechanical Twin Lamellae
}

\author{
By Kenji Morii*† and Yutaka Nakayama*
}

\begin{abstract}
The deformation behavior of a crystal containing mechanical twin lamellae has been examined from a view point of deformation geometry, and a two-dimensional model for the nucleation of shear bands has been proposed. It is suggested that in the crystal having $(111)[\overline{2} 11]^{\mathrm{M}}\left(+(111)[211]^{\mathrm{T}}\right)$ orientation, six types of shear localization are possible to occur and two families of shear bands can be nucleated. The shear bands expected show the inclination of about $\pm 20^{\circ}-35^{\circ}(0.35-0.61 \mathrm{rad})$ with respect to the twin lamellae and have the preferred orientation $\{011\}\langle 100\rangle$ and $\{211\}\langle 111\rangle$, in agreement with experimental results. The possibility of shear band formation in the other orientation is also discussed.
\end{abstract}

(Received July 2, 1983)

\begin{abstract}
Keywords : deformation, strain localization, shear bands, mechanical twin lamellae, fcc single crystal, rolling
\end{abstract}

\section{Introduction}

Many studies are available as for the microstructural features of shear bands in rolled $f c c$ materials ${ }^{(1)-(8)}$. One of the most remarkable results of these studies is the fact that the shear bands in materials with lower stacking fault energy are always accompanied by the lamellae of mechanical twins, but no shear bands are formed in the crystals or grains unfavorable to mechanical twinning during rolling. It is clear, therefore, that the occurrence of shear bands in these materials is closely connected with the mechanical twin lamellae.

Dillamore et al. ${ }^{(9)}$ and Houtte et al. ${ }^{(10)}$ have analyzed the shear band formation on the basis of the Taylor model, and came to the conclusion that geometric or textural softening of rolled materials plays an important role in the development of shear bands. However, the correlation between the shear bands and the mechanical twin lamellae is not fully understood.

The authors ${ }^{(11)(12)}$ have investigated the shear bands in copper single crystals rolled at the liquid nitrogen temperature, and shown that the inhomogeneous straining of mechanical twin la-

* College of Engineering, University of Osaka Prefecture, Mozu-Umemachi, Sakai 591, Japan.

$\dagger$ Now at Technical University, Hamburg-Harburg, West Germany. mellae is one of the causes of the nucleation of shear bands. In the present study, based on these experimental results, a geometric model for the shear band formation is examined in a crystal containing mechanical twin lamella. Comparison with the experimental results will be discussed in a succeeding paper (Part II).

\section{Shear Band Formation}

\section{Review of experimental findings ${ }^{(11)(12)}$}

The process of shear band formation was observed in (211) [1111] copper single crystals rolled at the liquid nitrogen temperature by means of an optical and transmission electron microscopy. Main results are summarized as follows:

Mechanical twinning induced during rolling yielded thin alternate layers of twin/matrix parallel to one of active slip planes. Usually the twin lamellae contained local heterogeneities such as misalignment and thickness variation of the component layers. As the rolling reduction increased, the twin lamellae developed further, and at the same time the twin lamellae which had been formed in foregoing reductions were also strained. In this case, the deformation of the twin lamellae was not homogeneous but tended to be localized into the regions with the heterogeneities given above. As a result, the twin lamellae 
showed localized deformation like an internal necking. It was also found that larger lattice rotation was generated within the necked regions. The shear localization in these regions led to the nucleation of microshear bands. Furthermore, the strain accumulated in the shear bands was accommodated by activating additional slip and twinning in the matrix regions, and then the shear bands grew into those penetrating many of the twin lamellae.

\section{Geometric consideration}

It is apparent from the above results that the shear band formation is controlled by the deformation of mechanical twin lamellae and their microstructures.

Next, let us consider the deformation behavior of a sheet-like crystal which contains mechanical twin lamellae composed of thin layers of twin/matrix, as shown in Fig. 1. For simplicity, it is assumed that the crystal has the (111) [211] orientation and the twin lamellae are disposed parallel to the sheet plane of the crystal, i.e. the twin layers have the (111) [ $2 \overline{1} \overline{1}]$ orientation. It is also supposed that the crystal is deformed under the pure shear stress system, in which tensile- and compressive-stress act, respectively, in $\mathrm{x}$ - and zdirection (Fig. 1). The deformation of the crystal will cause neither additional mechanical twinning nor the stiff rotation of the existing twin lamellae. The deformation behavior is regarded as "two dimensional" in $\mathrm{x}-\mathrm{z}$ plane, since the

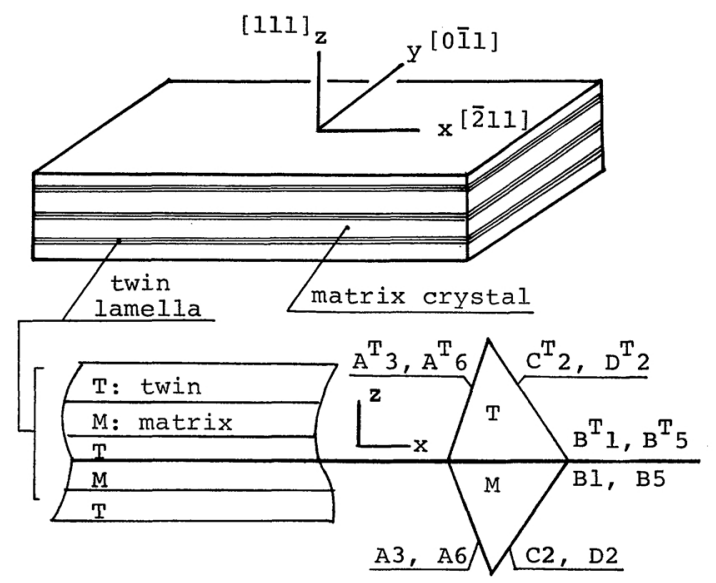

Fig. 1 Schematic illustration of a crystal containing mechanical twin lamellae. Slip systems are denoted on the (011) sections of Thompson's tetrahedra. geometry of slip systems in this crystal is symmetric against the y-plane (Fig. 1).

The crystal containing the mechanical twin lamellae can be considered as a composite. Since the twin lamellae consisted of fine layeredstructure of twin/matrix, the twin lamellae correspond to a harder phase, while the matrix crystals (see Fig. 1) behave as a softer phase. Upon straining such composite crystal, it is assumed that homogeneous deformation takes place unless shear localization occurs in the component layers.

As the stress axis in z-direction is normal to the interfaces of the twin/matrix lamellae, it is considered that the applied stress, $\sigma_{\mathrm{z}}{ }^{\mathrm{A}}$, is constant in both twin lamellae and matrix crystals. On the other hand, the stress axis $\mathrm{x}$ is parallel to the interfaces, so that though the average flow stress in $\mathrm{x}$-direction is $\sigma_{\mathbf{X}}{ }^{\mathrm{A}}$, both phases are deformed under different local flow stresses, $\sigma^{\mathrm{T}}$ and $\sigma^{\mathrm{M}}$, i.e.

$$
\sigma_{\mathbf{X}}{ }^{\mathrm{A}}=f^{\mathrm{T}} \sigma^{\mathrm{T}}+f^{\mathrm{M}} \sigma^{\mathrm{M}},
$$

where $f$ is the volume fraction of the phases, $\sigma^{\mathrm{T}}$ and $\sigma^{\mathrm{M}}$ are the local flow-stresses and the superscripts $T$ and $M$ refer to the twin lamellae and matrix crystals respectively. From the eq. (1) and the relation,

$$
f^{\mathrm{T}}+f^{\mathrm{M}}=1,
$$

the following equations can be obtained:

$$
\sigma^{\mathrm{T}}=\sigma_{\mathbf{X}}^{\mathrm{A}}+f^{\mathrm{M}}\left(\sigma^{\mathrm{T}}-\sigma^{\mathrm{M}}\right) \equiv \sigma_{\mathbf{X}}^{\mathrm{A}}+\Delta \sigma^{\mathrm{T}}
$$

and

$$
\sigma^{\mathrm{M}}=\sigma_{\mathrm{X}}^{\mathrm{A}}+f^{\mathrm{T}}\left(\sigma^{\mathrm{M}}-\sigma^{\mathrm{T}}\right) \equiv \sigma_{\mathrm{X}}^{\mathrm{A}}+\Delta \sigma^{\mathrm{M}},
$$

where $\left(\sigma^{\mathrm{T}}-\sigma^{\mathrm{M}}\right) \geqq 0$, as mentioned above. The terms, $\Delta \sigma^{\mathrm{T}}\left(=f^{\mathrm{M}}\left(\sigma^{\mathrm{T}}-\sigma^{\mathrm{M}}\right)\right)$ and $\Delta \sigma^{\mathrm{M}}\left(=f^{\mathrm{T}}\left(\sigma^{\mathrm{M}}\right.\right.$ $\left.-\sigma^{\mathrm{T}}\right)$ ), set up no external effects as a whole:

$$
f^{\mathrm{T}} \Delta \sigma^{\mathrm{T}}+f^{\mathrm{M}} \Delta \sigma^{\mathrm{M}}=0 .
$$

However, it is clear from eqs. (3) and (4) that the term $\Delta \sigma^{\mathrm{T}}$ aids the applied stress $\sigma_{\mathrm{X}}{ }^{\mathrm{A}}$ in the harder phase (twin lamellae), while the term $\Delta \sigma^{\mathrm{M}}$ opposes $\sigma_{\mathbf{X}}{ }^{\mathbf{A}}$ in the softer phase (matrix crystals). This feature may be characteristic in the deformation of composite materials ${ }^{(13)(14)}$.

If the density of the twin lamellae is very low as compared with that of the matrix crystals, i.e. the thickness of the twin lamellae is thin, the term $\Delta \sigma^{\mathrm{T}}$ in eq. (3) can not be neglected. Therefore, the 
stress state in the twin lamellae may be expressed referring to the specimen coordinates (Fig. 1):

$$
\boldsymbol{\sigma}=\left[\begin{array}{ccl}
\sigma_{\mathrm{X}}{ }^{\mathrm{A}}+\Delta \sigma^{\mathrm{T}} 0 & 0 \\
0 & 0 & 0 \\
0 & 0 & \sigma_{\mathrm{Z}}{ }^{\mathrm{A}}
\end{array}\right] \equiv\left[\begin{array}{ccc}
(1+\alpha) \sigma^{\mathrm{A}} 0 & 0 \\
0 & 0 & 0 \\
0 & 0 & -\sigma^{\mathrm{A}}
\end{array}\right],
$$

where $\Delta \sigma^{\mathrm{T}}=\alpha \sigma_{\mathrm{X}}^{\mathrm{A}}, \sigma_{\mathrm{X}}^{\mathrm{A}}=-\sigma_{\mathrm{Z}}^{\mathrm{A}}=\sigma^{\mathrm{A}}$. The resolved shear stress $(\tau)$ operated in the slip systems in the twin lamellae is calculated from eq. (6). The Schmid factors $\left(\tau / \sigma^{\mathbf{A}}\right)$ for various slip systems are shown in Fig. 2 as a function of the orientation, $\theta$, for various $\alpha$ 's. It is found in this figure that both sets of slip systems, A3, A6 and C2, D2, have the highest Schmid factor at the orientation $\theta=0$, (111) [ $\overline{2} 11]$, and that the term $\Delta \sigma^{\mathrm{T}}\left(=\alpha \sigma_{\mathrm{X}}^{\mathrm{A}}\right)$ aids the activation of the slip systems in the twin lamellae (harder phase).

Now, it is supposed that these two sets of slip systems are activated in every layer of the twin/matrix, and that the effects of twin boundaries on the deformation are neglected. The deformation in the twin or matrix layer can be

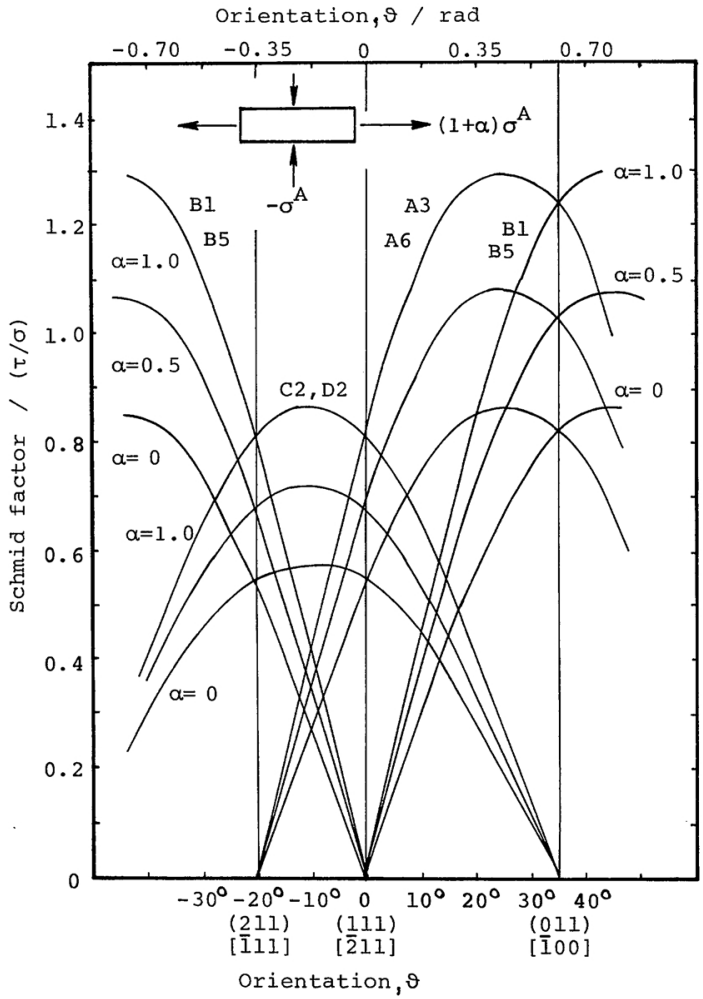

Fig. 2 Schimd factors for various slip systems under the biaxial stress system. written in terms of a deformation gradient matrix, $\boldsymbol{F}$, referring to the cubic coordinates (see Appendix $)^{(15)}$ :

$$
\begin{aligned}
& \boldsymbol{F}=\frac{1}{4 a} \\
& {\left[\begin{array}{lcc}
2(a \mathrm{X}+\mathrm{Y}) & -2 \mathrm{Y} & -2 \mathrm{Y} \\
-\left(a^{2}-1\right) \mathrm{Y} & a \mathrm{X}-\mathrm{Y}+2 a & a \mathrm{X}-\mathrm{Y}-2 a \\
-\left(a^{2}-1\right) \mathrm{Y} & a \mathrm{X}-\mathrm{Y}-2 a & a \mathrm{X}-\mathrm{Y}+2 a
\end{array}\right],}
\end{aligned}
$$

where $a=\sqrt{2 \beta}, \beta$ is the ratio of the glide shears, $\gamma$ 's, on the slip systems, A3, A6 and C2, D2, X $=\exp (c)+\exp (-c), \mathrm{Y}=\exp (c)-\exp (-c)$ and $c=2 \sqrt{\beta} \gamma / \sqrt{3}$. During such deformation the lattice rotation, $\delta$, occurs in the layer about $y$ axis :

$$
\delta=\cos ^{-1}\left[\left(3 a X+2 Y+a^{2} Y\right) / 6 a e\right],
$$

where $e$ is the elongation of the layer in $\mathrm{x}$ direction. In Fig. 3, the rotation angle, $\delta$ 's, are plotted as a function of the elongation, $e$, for various $\beta$ 's. The figure shows that (111) [ $\overline{2} 11]$ orientation is stable for $\beta=1 / 2$, but in the case of equal operation of these slip systems, $\beta=1$, the orientation changes toward the (011) [100].

If homogeneous deformation occurs in both twin and matrix layers, the deformation behavior of the twin lamellae may be described by eqs. (7) and (8). As noted in Section II-1, however, the mechanical twin lamellae are usually

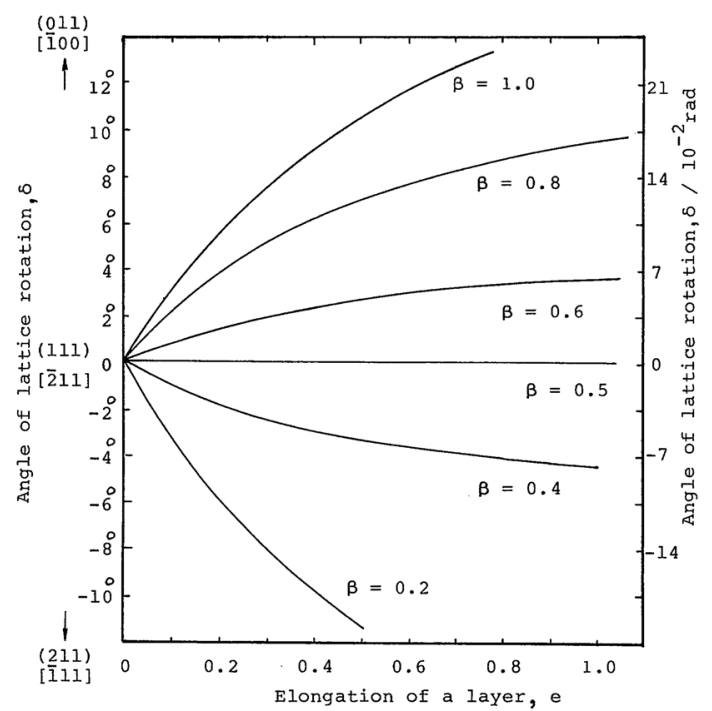

Fig. 3 Lattice rotation in the twin/matrix layer as a function of the elongation $e=l / l_{0}$ (eq. (8)). 
accompanied by local heterogeneities such as the variation of twin density. This may cause inhomogeneous deformation of the twin lamellae. For example, the local variation of thickness in the component layers causes the fluctuation of the local flow stress, $\sigma:^{(16)}$

$$
\sigma=\sigma_{0}+\mathrm{k} \lambda^{-\varphi},
$$

where $\sigma_{0}$ is a frictional stress, $k$ is a constant, $\lambda$ is a mean thickness of the layers and $\varphi$ is a constant of the order of $1 / 2-1$. This equation suggests that the regions having larger $\lambda$ can be deformed under lower stress. It is considered, therefore, that the deformation of the twin lamellae tends to be localized into these regions and becomes inhomogeneous.

Once the localized deformation begins to occur in the regions having larger $\lambda$, the stress concentration inevitably occurs at the intersections of the slip zones and the twin/matrix layers, since twin boundaries act as barriers for slip, as shown in the insert of Fig. 4. As a first approximation, the stress concentration may be expressed by the pile-ups of dislocations; the stress at the head of pile up dislocations, $\tau^{\mathrm{P}}$, is given by $\tau^{\mathrm{P}}=n \tau$, where $n$ is the number of pile up dislocations and $\tau$ is the shear stress on the operating slip system. If the stress concentration is assumed to be released by the activation of slip systems in neighbouring layers, the stress, $\tau^{\mathbf{N}}$, acting on each slip system is expressed $a s^{(17)}$

$$
\tau^{\mathrm{N}}=\left(g_{11} g_{22}+g_{12} g_{21}\right) \tau^{\mathrm{P}} \equiv \mathrm{N} \tau^{\mathrm{P}},
$$

where $g$ 's are the direction cosines between the coordinates of the operating slip system and the slip system in the neighbouring layers (1: slip direction, 2 : normal direction of slip plane). The factors, N's, are plotted in Fig. 4 as a function of $\psi$, the direction of slip zone (see the insert of Fig. 4), for various slip systems. It is supposed for calculating the factor $\mathrm{N}$ in eq. (10) that the slip zone has a plane shape which is perpendicular to y-plane. It is noted in Fig. 4 that the localized slip in one of the layers assists the activation of the slip systems, A3, A6 and C2, D2, in the neighbouring layers for $\psi= \pm 20^{\circ}-35^{\circ}$ (0.35-0.61 rad). As a result of this behavior, the localized deformation initiated in some of the component layers is able to propagate gradually into surrounding layers, and the locally defor-

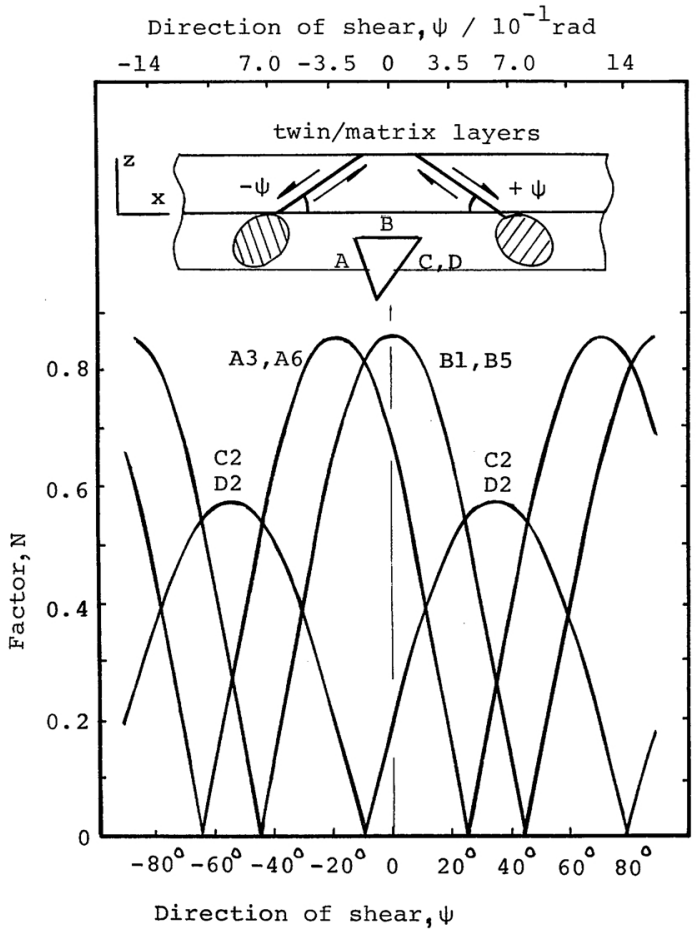

Fig. 4 Effect of localized shear on the shear stress of the slip systems in neighbouring layers (eq. (10)).

med regions may develop like the internal necking of the twin lamellae.

If the strain in these regions governs the total elongation of a twin lamella, an inhomogeniety factor, $\eta$, of the strain localization may be introduced:

$$
\eta=e^{\mathrm{L}} / \bar{e}=\bar{l} / l^{\mathrm{L}}
$$

where $\bar{e}=\Delta l^{\mathrm{L}} / \bar{l}, e^{\mathrm{L}}=\Delta l^{\mathrm{L}} / l^{\mathrm{L}}$, total and local elongations of the twin lamella, and $\bar{l}$ and $l^{\mathrm{L}}$ are, respectively, the mean separation of the locally deformed regions and the mean length of these regions (see Fig. 5). The lattice rotation in the regions of localized deformation is estimated from eq. (8) and Fig. 3 by putting $e^{\mathrm{L}}$ instead of $e$. It is found that when $\eta$ is very large, i.e. larger inhomogeneity exists, even in lower total strain of the twin lamella, a greater amount of strain accumulates and, therefore, severe lattice rotation to (011) [100] or (211) [111] occurs in the locally deformed regions providing $\beta \simeq 1$ or $\beta$ $\simeq 0$. The Schmid factors of the operative slip systems increase greatly with such lattice rotation, as seen in Fig. 2. Then, it can be said that 


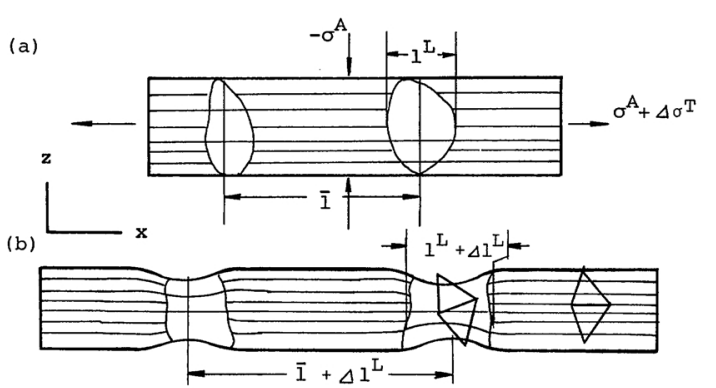

Fig. 5 Schematic illustration of local deformation in a twin lamella; (a) before and (b) after deformation.

the locally deformed regions show geometric softening of operative slip systems. This feature of slip systems may play an important role in the localization of shear deformation within the twin lamella, i.e. the shear band nucleation.

The localized shear deformation in one of the twin lamellae can also extend over neighbouring matrix crystals by introducing the stress concentration and by activating particular slip systems; this is similar to that found in the deformation of the twin/matrix layers, as described above (Fig. 4). The localized shear deformation or shear bands induced in a twin lamella, therefore, grow to penetrate several twin lamellae.

\section{Two-dimensional model of shear banding}

The nucleation of the shear bands are examined on the geometrical view point. Suppose that the preferential straining occurs in a layer of larger thickness within a twin lamella, and propagates to neighbouring layers under the deformation conditions given in Section II-2. The morphology of the shear localization is classified depending on whether the straining layer is a twin or matrix, and on the kind of operative slip systems. Assuming also that the shear localization across the twin/matrix layers is favorable for the slip planes disposed normal to y-plane in both layers. Six types of the shear localization are modeled in Fig. 6. Though the figure shows the model for the shear localization initiated in the twin layer, the same is expected in the case of the matrix layer, since the geometry of slip systems in both layers is symmetric with respect to $\mathrm{z}$-plane. In Table 1, the processes of the shear localization in Fig. 6 are summarized. For example, the shear localization of the type 2(T) (Fig. 6(b)) is interpreted as follows: The preferential operation of the slip systems, $\mathrm{A}^{\mathrm{T}} 3$ and $\mathrm{A}^{\mathrm{T}} 6$, in the twin layer leads to the lattice rotation toward the $(011)$ [100] orientation so that the slip systems, $\mathrm{B}^{\mathrm{T}} 1$ and $\mathrm{B}^{\mathrm{T}} 5$, are activated (Figs. 2 and 3 ). The stress concentration due to slip on $\mathrm{B}^{\mathrm{T}}$ plane aids the activation of $\mathrm{C} 2$ and $\mathrm{D} 2$ systems in the neighbouring matrix-layers (Fig. 4). This causes also the lattice rotation to the (211) [111] (or (1144) [81111]), and then the slip systems, B1 and B5, become operative (Figs. 2 and 3 ) in the matrix layer. Preferred slip on $\mathrm{B}^{\mathrm{T}}$ and on $\mathrm{B}$ results in the shear localization across the twin/matrix layers, that is the nucleation of shear bands.
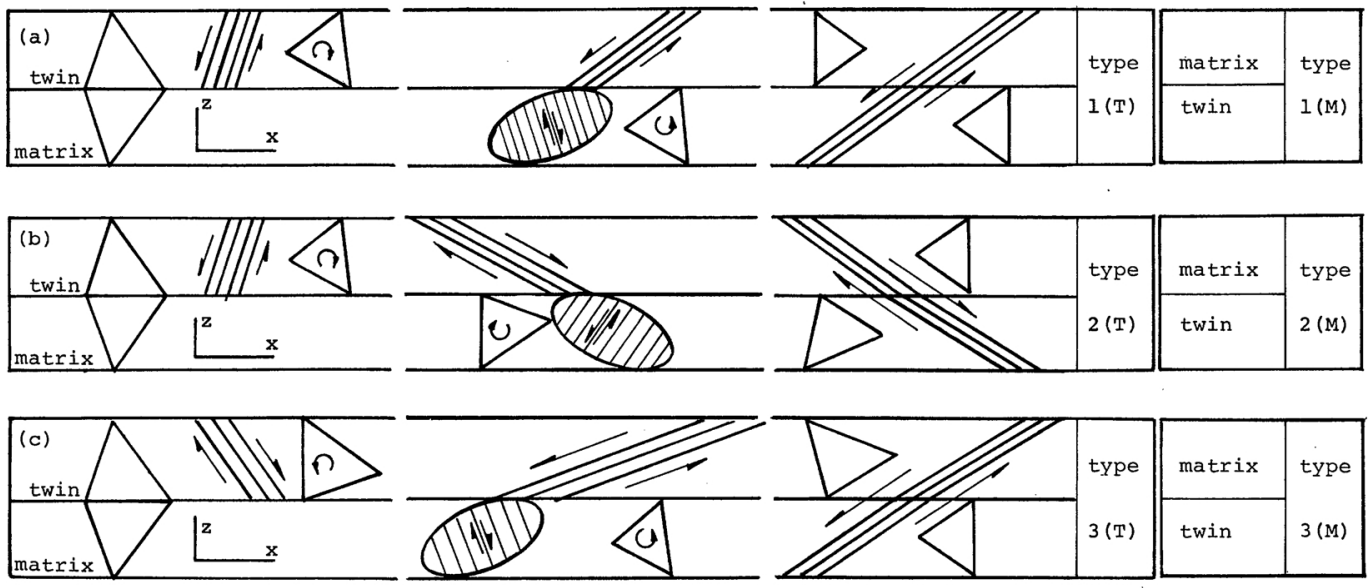

Fig. 6 Schematic illustration of the process of shear band nucleation in the twin/matrix layers. The orientation of the layer is expressed by the $(0 \overline{1} 1)$ section of Thompson's tetrahedron. 
Table 1 Six types of shear localization in Fig. 6.

\begin{tabular}{|c|c|c|c|c|c|c|c|}
\hline & Type & $1(\mathrm{~T})$ & $1(\mathrm{M})$ & $2(\mathrm{~T})$ & $2(\mathrm{M})$ & $3(\mathrm{~T})$ & $3(\mathrm{M})$ \\
\hline \multirow{4}{*}{ 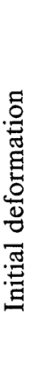 } & $\begin{array}{c}\text { Straining } \\
\text { layer }\end{array}$ & twin & matrix & twin & matrix & twin & matrix \\
\hline & $\begin{array}{l}\text { Preferred } \\
\text { slip } \\
\text { systems* }\end{array}$ & $A^{T} 3, A^{T} 6$ & $\mathrm{~A} 3, \mathrm{~A} 6$ & $A^{T} 3, A^{T} 6$ & $\mathrm{~A} 3, \mathrm{~A} 6$ & $\mathrm{C}^{\mathrm{T}} 2, \mathrm{D}^{\mathrm{T}} 2$ & $\mathrm{C} 2, \mathrm{D} 2$ \\
\hline & $\begin{array}{l}\text { Lattice } \\
\text { rotation } \\
\text { toward** }\end{array}$ & (011) [100] & (011) $[\overline{1} 00]$ & (011) [100] & $(011)[\overline{1} 00]$ & $(211)[1 \overline{1} \overline{1}]$ & $(211)[\overline{1} 11]$ \\
\hline & $\begin{array}{l}\text { Activated } \\
\text { slip } \\
\text { systems*** }\end{array}$ & - & - & $\mathrm{B}^{\mathrm{T}} 1, \mathrm{~B}^{\mathrm{T}} 5$ & B1, B5 & $\mathrm{B}^{\mathrm{T}} 1, \mathrm{~B}^{\mathrm{T}} 5$ & B1, B5 \\
\hline \multirow{6}{*}{ 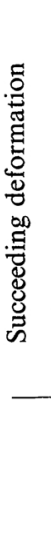 } & $\begin{array}{c}\text { Straining } \\
\text { layer }\end{array}$ & matrix & twin & matrix & twin & matrix & twin \\
\hline & $\begin{array}{l}\text { Preferred } \\
\text { slip } \\
\text { systems* }\end{array}$ & $\mathrm{A} 3, \mathrm{~A} 6$ & $\mathrm{~A}^{\mathrm{T}} 3, \mathrm{~A}^{\mathrm{T}} 6$ & $\mathrm{C} 2, \mathrm{D} 2$ & $\mathrm{C}^{\mathrm{T}} 2, \mathrm{D}^{\mathrm{T}} 2$ & $\mathrm{~A} 3, \mathrm{~A} 6$ & $\mathrm{~A}^{\mathrm{T}} 3, \mathrm{~A}^{\mathrm{T}} 6$ \\
\hline & $\begin{array}{l}\text { Lattice } \\
\text { rotation } \\
\text { toward** }\end{array}$ & (011) [100] & (011)[100] & (211) [ī11] & (211) [11̄̄î] & (011) [1̄00] & (011) [100] \\
\hline & $\begin{array}{l}\text { Activated } \\
\text { slip } \\
\text { systems*** }\end{array}$ & B1, B5 & $\mathrm{B}^{\mathrm{T}} 1, \mathrm{~B}^{\mathrm{T}} 5$ & B1, B5 & $\mathrm{B}^{\mathrm{T}} 1, \mathrm{~B}^{\mathrm{T}} 5$ & B1, B5 & $\mathrm{B}^{\mathrm{T}} 1, \mathrm{~B}^{\mathrm{T}} 5$ \\
\hline & $\begin{array}{l}\text { Shear } \\
\text { localization }\end{array}$ & $\mathrm{A}^{\mathrm{T}}-\mathrm{B}$ & $\mathrm{A}-\mathrm{B}^{\mathrm{T}}$ & $\mathbf{B}^{\mathrm{T}}-\mathrm{B}$ & $\mathrm{B}-\mathrm{B}^{\mathrm{T}}$ & $\mathrm{B}^{\mathrm{T}}-\mathrm{B}$ & $\mathrm{B}-\mathrm{B}^{\mathrm{T}}$ \\
\hline & $\begin{array}{c}\text { Inclination } \\
\qquad \psi\end{array}$ & - & + & + & - & - & + \\
\hline
\end{tabular}

* see Fig. 2, **see Fig. 3, ***see Fig. 4.

\section{Discussion}

Depending on the microstructural heterogeneities in the mechanical twin lamellae, various types of the shear localization can be introduced as described above. It should be noted in Fig. 6 and Table 1 that the shear localization results from the preferred slip on $\mathrm{B}$ or $\mathrm{B}^{\mathrm{T}}$ plane, the twinning plane of the crystal considered. Within the locally deformed regions, due to the lattice rotation, the slip plane, $\mathrm{B}$ or $\mathrm{B}^{\mathbf{T}}$, is reoriented so as to incline against the twin lamella (Fig. 5), and shows the geometric softening (Fig. 2). Therefore, the slip systems on this plane can operate as a glide system across the twin/matrix layers. Preferential activation of this glide system may easily be expected to nucleate the shear bands in the twin lamellae.
In the $(111)[\overline{2} 11]^{\mathrm{M}}\left(+(111)[2 \overline{1} \overline{1}]^{\mathrm{T}}\right)$ crystal, six types of the shear localization are possible to nucleate the shear bands, which have the preferred orientation of $\{011\}\langle 100\rangle$ or $\{211\}$ $\langle 111\rangle(\{1144\}\langle 81111\rangle)$ and the inclination of $\pm 20^{\circ}-35^{\circ}$ with respect to the twin lamella. The inclination of the shear bands shows $\psi>0$ for the types, 1(M), 2(T) and 3(M), while $\psi<0$ for the types, $1(\mathrm{~T}), 2(\mathrm{M})$ and $3(\mathrm{~T})$. Then, so-called two families of shear bands are formed in this orientation. These conclusions agree well with the experimental findings ${ }^{(6)-(8)(11)(12)}$ that many of the shear bands in the mechanical twin lamellae exhibited the inclination given above and the $\{011\}\langle 100\rangle$ texture. The $\{211\}\langle 111\rangle$ orientation is considered to be diminished by further mechanical twinning.

It is suggested also that the shear bands are formed in the other crystals, so far as the crystals 
contain the mechanical twin lamellae and are deformed by activating particular slip systems. For examples, in the $(211)[\overline{1} 11]^{\mathrm{M}}\left(+(255)[5 \overline{1} \overline{1}]^{\mathrm{T}}\right)$ crystal, the shear bands of the types, 1(T), 2(T) and $3(\mathrm{M})$, may be nucleated, because the slip systems, $\mathrm{A}^{\mathrm{T}} 3, \mathrm{~A}^{\mathrm{T}} 6$, and $\mathrm{C} 2, \mathrm{D} 2$, can operate in this orientation. On the other hand, in the (011) $[\overline{1} 00]^{\mathrm{M}}\left(+(411)[1 \overline{2} \overline{2}]^{\mathrm{T}}\right)$ crystal, the activation of the slip systems, $\mathrm{A} 3, \mathrm{~A} 6$, and $\mathrm{C}^{\mathrm{T}} 2, \mathrm{D}^{\mathrm{T}} 2$, may form the shear bands of the types, $1(\mathrm{M}), 2(\mathrm{M})$ and $3(\mathrm{~T})$. Preliminary experiments showed the shear bands of the types, $2(\mathrm{~T})$ and $3(\mathrm{M})$, in the (211) $[\overline{1} 11]^{\mathrm{M}}\left(+(255)[5 \overline{1} \overline{1}]^{\mathrm{T}}\right)$ copper single crystals rolled at room temperature ${ }^{(11)}$. Based on the proposed model, detailed experimental results will be discussed in a succeeding paper (Part II) $)^{(18)}$.

\section{Conclusion}

The deformation behavior of a crystal containing the mechanical twin lamellae was examined, and the shear bands formation was discussed from the view point of deformation geometry. The crystal was regarded as a composite which consisted of harder twin lamellae and softer matrix crystals. It was pointed out that the microstructural heterogeneities inherent in the mechanical twin lamellae such as the variation of twin density played a dominant role in the shear localization in the twin lamellae. The geometric softening of operative slip systems occurs due to the lattice rotation induced within the locally deformed regions. The shear localization can, therefore, progress increasingly to nucleate the shear bands. On the basis of this view, the twodimensional model of the shear band formation was inferred (Fig. 6 and Table 1).

\section{REFERENCES}

(1) M. Blicharski and S. Gorczyca: Met. Sci., 12 (1978), 303.

(2) B. J. Duggan, M. Hatherly and W. B. Huchinson: Met. Sci., 12 (1978), 343.

(3) P. T. Wakefield and M. Hatherly: Met. Sci., 15 (1981), 109.

(4) M. Hatherly: Proceedings of 5th International Conference on Textures of Materials, Ed. by G. Gottstein and K. Lüke, Springer-Verlag, (1978), p. 81.

(5) B. Plege, T. Noda und H. Bunge: Z. Metallk., 72 (1981), 641.

(6) K. Morii, M. Mera and Y. Nakayama: Trans. JIM, 18
(1977), 7.

(7) K. Morii, M. Mera and Y. Nakayama: Trans. JIM, 21 (1980), 20.

(8) Y. Nakayama, Y. Tatusmi, M. Mera and K. Morii: J. Japan Inst. Metals, 43 (1979), 29 (in Japanese).

(9) I. L. Dillamore, J. G. Roberts and A. C. Bush : Met. Sci., 13 (1979), 73.

(10) P. V. Houtte, J. Gil Sevillano and E. Aernoudt: Z. Metallk., 70 (1979), 426 and 503.

(11) K. Morii and Y. Nakayama: Trans. JIM, 22 (1981), 857.

(12) Y. Nakayama and K. Morii: Trans. JIM, 23 (1982), 422.

(13) S. L. Semiatin and H. R. Piehler: Met. Trans., 10A (1979), 97.

(14) H. Mughrabi: Acta Met., 31 (1983), 1367.

(15) G. Y. Chin, R. N. Thurston and E. A. Nesbitt: Trans. Met. Soc. AIME, 236 (1966), 69.

(16) D. A. Porter, K. E. Easterling and G. D. W. Smith: Acta Met., 26 (1978), 1405.

(17) J. D. Livingston and B. Chalmers: Acta Met., 5 (1957), 322.

(18) K. Morii and Y. Nakayama: to be published.

\section{Appendix $^{(15)}$}

When a material deforms homogeneously, the movement of a material point is described by the deformation gradient matrix :

$$
F_{i j}=\partial X_{i} / \partial x_{j}, \quad i, j=1,2,3
$$

where $X_{i}\left(X_{1}, X_{2}, X_{3}\right)$ and $x_{j}\left(x_{1}, x_{2}, x_{3}\right)$ are the coordinates of the material points before and after the deformation respectively. During the deformation a material line having an unit vector $U_{k}\left(U_{1}, U_{2}, U_{3}\right)$ is transformed into $u_{1}\left(u_{1}, u_{2}, u_{3}\right)$ :

$$
u_{i}=F_{i j} U_{j}
$$

where the summation over repeated subscripts is implied.

For the material deformed by crystallographic slip, $F_{i j}$ is expressed as:

$$
\begin{aligned}
& F_{i j}=\exp \left(\gamma f_{i j}\right) \\
& f_{i j}=b_{i}^{\mathrm{s} 1} n_{j}^{\mathrm{s} 1}+\beta_{2} b_{i}^{\mathrm{s} 2} n_{j}^{\mathrm{s} 2}+\beta_{3} b_{i}^{\mathrm{s} 3} n_{j}^{\mathrm{s} 3}+\cdots
\end{aligned}
$$

where $b_{i}$ and $n_{j}$ are respectively the components of the unit slip vector and unit normal of the slip plane for slip systems, s1, s2 and s3 $\cdots$ and $\beta_{2}$ $=\gamma^{\mathrm{s} 2} / \gamma^{\mathrm{s} 1}, \beta_{3}=\gamma^{\mathrm{s} 3} / \gamma^{\mathrm{s} 1}, \cdots$, the ratios of the glide shear $(\gamma$ 's) on the slip systems.

As for the crystal (111) [2111], that considered in Section II-2, the activation of the following 


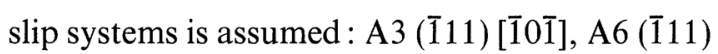
[ $\overline{1} \overline{1} 0], C 2(1 \overline{1} 1)[0 \overline{1} \overline{1})], D 2(11 \overline{1})[0 \overline{1} \overline{1}]$. From the geometric symmetry, the glide shears in these slip systems are also supposed as:

$$
\gamma^{\mathrm{A} 3}=\gamma^{\mathrm{A} 6} \equiv \gamma, \gamma^{\mathrm{C} 2}=\gamma^{\mathrm{D} 2}=\beta \gamma
$$

Using the eqs. (A3) and (A4), the deformation gradient matrix is given refer to the cubic coordinates ([100], [010], [001]):

$$
F_{i j}=\frac{1}{4 a}\left[\begin{array}{ccc}
2(a \mathrm{X}+\mathrm{Y}) & -2 \mathrm{Y} & -2 \mathrm{Y} \\
-\left(a^{2}-1\right) \mathrm{Y} & a \mathrm{X}-\mathrm{Y}+2 a & a \mathrm{X}-\mathrm{Y}-2 a \\
-\left(a^{2}-1\right) \mathrm{Y} & a \mathrm{X}-\mathrm{Y}-2 a & a \mathrm{X}-\mathrm{Y}+2 a
\end{array}\right]
$$

where $a=\sqrt{2 \beta}, \mathrm{X}=\exp (c)+\exp (-c), \mathrm{Y}=$ $\exp (c)-\exp (-c)$ and $c=2 \sqrt{\beta} \gamma / \sqrt{3}$. The orientational change during deformation can be obtained from eqs. (A2) and (A5), since the material line parallel to $x$-direction, i.e. the rolling direction [ $\overline{2} 11]$, is maintained always parallel to $\mathrm{x}$-direction. Then, the angle of the lattice rotation, $\delta$, is given by the angle between two vectors, $U_{i}$ and $u_{j}$ :

$$
\cos \delta=\left(3 a \mathrm{X}+2 \mathrm{Y}+a^{2} \mathrm{Y}\right) / 6 a e
$$

where $e\left(=l / l_{o}\right)$ is the elongation of the material line along the $\mathrm{x}$-direction. 